\title{
THE EVALUATION OF THE RATE AND THE TYPE OF MEDICATION ERRORS AMONG NURSES
}

\author{
ZAHRA POURNAMDAR ${ }^{1}$, SADEGH ZARE ${ }^{2 *}$
}

${ }^{1}$ Department of Nursing, Community Nursing Research Center, Pregnancy Health Research Center, Zahedan University of Medical Sciences, Zahedan, Iran. ${ }^{2}$ Department of Nursing, Student Scientific Research Center, Zahedan University of Medical Sciences, Zahedan, Iran. Email: zaresadegh93@yahoo.com

Received: 26 April 2016, Revised and Accepted: 30 June 2016

\section{ABSTRACT}

Objective: Since medication instructions are an important part of patients' treatment process, neglecting the correct principles of medication instructions application can result in numerous problems such as unsuccessful treatment or failure and the emergence of lawsuit and complaint issues. The survey and the determination of the medication error types is the first step in preventing them and since the medication errors are common among the nurses according to the various studies and due to their importance the researchers decided to perform a study aiming at the survey of the rate and the type of the medication errors common among the nurses.

Methods: This study is a descriptive research performed on 119 nurses from Zahedan training hospitals all of whom have been selected based on a random method in 2016. To gather the necessary information required for the current study, a two-part questionnaire was taken advantage of the first part of which was related to the demographic characteristics, and the second part was connected to the evaluation of the type of medication errors and reporting them. Finally, after the questionnaires were collected, the data were analyzed based on SPSS 19 software and descriptive statistics.

Results: The participants average age was $28.86 \pm 6.45 ; 101$ individuals were women and 87 individuals had passed courses on ethics. Furthermore, 86 nurses had had an experience of medication error at least for 1 time. The highest mean score in the type of the medication error was related to "wrong infusion rate, wrong dosage, and administering several drugs without paying attention to the drug interferences."

Conclusion: In this study, the results indicated that the rate of the medication errors is a very high among the nurses. Therefore, to reduce the medication errors, there is a need for making serious decisions.

Keywords: Medication error, Nurses, Zahedan.

(C) 2016 The Authors. Published by Innovare Academic Sciences Pvt Ltd. This is an open access article under the CC BY license (http://creativecommons. org/licenses/by/4. 0/) DOI: http://dx.doi.org/10.22159/ajpcr.2016.v9s2.12431

\section{INTRODUCTION}

Rapid changes in health and treatment systems have faced the clinical professional personnel with multiple ethical challenges $[1,2]$ Nowadays, medication errors are among the main concerns in the healthcare providing systems and due to the prevalence of the possible risks for the patients it is used for determining the patient safety rate in the hospitals [3]. Moreover, this is in a manner that some state 10-18\% of the hospital injuries as accounted for by the injuries originating from mediation errors [4,5]. Medication errors usually are a consequent of not correctly performing the responsibilities by the nurses, clinical personnel, physicians, and the pharmacologist or the patient himself Since mediation instructions are an integral part of patient's treatment process neglecting the correct principles regarding the application methodologies can result in great many of problems such as failure in treatment and the statutory issues [6]. Getting an overall image of the medication errors is difficult in developing countries. In Iran, although there is no available compiled and codified statistics regarding the rate of medication errors, thus the experts of the field estimate that this rate can be very high; the increase in the number of the people's complains from nurses and physicians to the medical system organization and filing lawsuits to the courts can be confirmatory of such an estimation [7,8]. Medication errors control is of a great importance since besides being costly its today's negative outcomes have been well-recognized regarding the patients who are the most significant priority of the countries health systems [9]. Drug prescription is a team work and an important, sensitive and complicated process which can take place in any stages in the process [10]. Medication errors can occur in various stages of administering drugs to the patients such as prescription, taking notes on physician's instruction, drug distribution and portioning, drug administration to the patients, or medication controlling cycle [11]. Medication errors are more in the venous injections in comparison to the other injection methods, even there are reports indicating the occurrence of severe injuries and death following intravenous injection mistakes including wrong drugs, wrong dosage, and wrong dilution rate [12]. The studies have shown that cases such as the lack of pharmacological information, incorrect drug calculations, violating the predetermined contracts, physicians' illegible handwriting, the existence of drug similarities and deficient and disturbed shapes and packaging, name similarities are among the factors contributing to the medication errors and factors such as shortage of time or the inadequacy of the tools and instruments, the insufficient number of personnel influence medication errors indirectly [13].

Mistakes and errors are inseparable from human deeds and performances, and they are part of human nature based on this the human role in the medication error occurrence has been completely accepted [14]. The survey and the determination of the errors is the first step in preventing them from happening and since according to the great many of the studies performed in this field medication errors are very common among the nurses and due to the importance of this subject matter the researchers decided to deal with the survey of the rate and type of the medication errors among the nurses.

\section{METHODS}

This study is a descriptive research which has been performed on 119 nurses in training hospitals in Zahedan all of whom have been 
selected randomly in 2016. To collect the information required for performing this study a two-part questionnaire was used the first part of which was belonged to demographic characteristics (age, gender, work history and having passed courses on ethics) and the second part was related to the evaluation of the type of medication errors which have been experienced by the nurses during the last 3 months. This questionnaire contained 17 items, and the individuals were supposed o tick and choose the item which had happened to them. This questionnaire was used in Isfahan by Amir et al. [15] and its validity has been confirmed, and the reliability of the questionnaire was obtained 0.91 based on Cronbach's alpha method.

To gather the data, after acquiring a confirmation letter from Zahedan medical university research vice chancellorship regarding the research plan and obtaining a letter of recommendation and making the necessary coordination jobs with the hospital the researcher referred to the hospital. First, the objective of this study was explained to the participants and acquiring an oral consent the questionnaire was distributed in sufficient number among the participants. At the beginning section of the questionnaire a text was inserted which indicated that the respondent are consciously aware of their cooperation with the research plan and it read that "the participants cooperation in the current study implies that they are fully aware of their cooperation and that the information provide by them is regarded as confidential, and they will not be exposed to any risks by any means." After the questionnaires were completed, they were collected and reviewed by the researcher, they were again returned to the respondents in case of existing incomplete parts, and they were asked to complete them. Finally, after the questionnaires were gathered, the data extracted from them was analyzed by taking advantage of SPSS 19 and descriptive statistics.

\section{RESULTS}

The participants average age was $28.86 \pm 6.45 ; 101$ individuals $(84.9 \%)$ were women and 87 individuals $(73.1 \%)$ had participated in courses on ethics previously. 64 individuals $(53.8 \%)$ had a work history ranging from 1 to 5 years, 38 individuals (31.9\%) had a work history of 5-10 years, 11 individuals (9.2\%) had a work history $10-15$ years, and 6 individuals $(5 \%)$ had a work history of more than 15 years. Furthermore, 86 individuals (72.3\%) had prior medication errors at least for 1 time. The highest mean scores regarding the type of medication error were related to "the wrong infusion rate, wrong dosage, and administering several drugs simultaneously without being aware of their interferences."

The frequency of the nurses' medication errors is given in Table 1.

\section{DISCUSSIONS}

The results of this study indicated that $72.3 \%$ of the nurses have once committed a medication error. Lisby et al. reported the rate of medication errors among the treatment and healthcare personnel as $43 \%$ in Denmark which has been lower than what has been obtained by this study [16]. In the study conducted by Stratton et al., $67 \%$ of the nurses who worked in the children sections reported that they had medication errors at least for 1 time [17]. The comparative analysis between the studies and results performed by the author of the current research indicated that medication error rate is very high among the nurses working in Zahedan training hospitals. The great difference in self-reported medication errors in Iran in comparison to the other countries can be due to the inaccurate supervision on the medication process and the absence of a definite and correct recording and reporting system. Drugs are the most common treatment commodity which is being applied in healthcare providing and treatment units. The abundance in drugs consumption and the necessity to make use of them can increase the error coefficient [4], and the medication errors can occur in each of the drugs prescription and distribution process; since prescribing drugs to the patients is a complex task and necessitates awareness, decision-making and correct performance by the staff working in the hospital departments and sections [18]. However, since a nurse can administer more than 50 drugs in a department or section of a hospital, she/he is more exposed to the risk of medication error [19] because it has been proved in some studies that there is a direct relationship between the nurses' length of working hours and the rate of the medication errors, and this is in a way that with the increase in the working hours the rate of medication errors also rise $[20,21]$. Therefore, it is suggested that the managers and the officials pay particular attention to the present subject and take serious steps in improving them. Updating nurses' information regarding the drugs, especially the new ones, can be considered as an important factor in reducing the medication errors.

The highest mean scores regarding the medication errors type were belonged to "wrong infusion rate, wrong dosage, and administering several drugs simultaneously without paying attention to the drug interferences". The results obtained in the study by Seydi which was conducted in the hospitals in Mashhad are also implying that the highest frequency of the medication errors in nurses was related to the wrong infusion rate and wrong dosage [22]. In the study performed by Dean et al., the most common medication errors in British nurses have been omissions and wrong infusion rate; and wrong infusion rate and administering drugs without being prescribed by the physician have been reported in American nurses which conform to the results obtained by the present study [23].

Table 1: The frequency of the nurses' medication error type

\begin{tabular}{lll}
\hline Questionnaire of medication error types & Absolute frequency & Relative frequency \\
\hline Wrong infusion rate (infusion drugs) & 36 & 30.3 \\
Administering wrong amount of drug (more or less than the prescribed dosage) & 36 & 30.3 \\
Administrating the drug in the wrong time (early or late) & 28 & 23.5 \\
Administration of several drugs simultaneously neglecting the drug interferences & 33 & 27.7 \\
Not diluting the drugs which have to be diluted or incorrect solvent volume & 14 & 11.8 \\
Administering the drug to wrong patient & 21 & 17.6 \\
Not observing the drug precautions & 18 & 15.1 \\
Wrong injection speed rate (intravenous drugs which should be injected slowly) & 25 & 21.0 \\
The application of expired drugs & 10 & 8.4 \\
Intravenous drugs injected subcutaneously & 9 & 7.6 \\
Intravenous drugs injected intramuscularly & 6 & 5.0 \\
Intravenous drugs injected intravenously & 12 & 10.1 \\
Administering drugs without physicians' prescription & 18 & 15.1 \\
Neglecting the laboratory recommended rates and dosages & 18 & 15.1 \\
Administering sublingual or buccal drugs orally & 11 & 9.2 \\
Forgetting to administer the prescribed drugs & 18 & 15.1 \\
Ignoring the patients' electrocardiogram and heart monitoring & 27 & 22.7 \\
\hline
\end{tabular}


In a study performed by Prot et al., 485 errors were observed which have been conducted by nurses and these included $36 \%$ of the errors happened at the time of administering drugs, 19\% of the errors occurred in the drug administering method, $15 \%$ were related to the amount of the drug, and $10 \%$ have been pertained to the drug administering without being prescribed by the physician [24]. In the study performed by Haw et al., it was indicated that the most common medication errors were wrong dosage (31\%), wrong drug $(21 \%)$, and forgetting to administer the drug (17\%) [25]. In the study performed by Wolf et al., the results were also suggestive of the most common medication error which was reported to be forgetting to administer the drug (19\%), wrong dosage (17.16\%), and wrong drug administration timing (16.93\%) [26]. In the study performed by Cavell and Oborne, $31.5 \%$ of the medication errors were connected to the intravenous injections [27].

A considerable part of the medical errors are the ones which are committed by the nursing staff while offering healthcare services, in such a manner that during the recent years due to the increase in the morbidity count and hospital costs undertaking medication errors researches and studies have grown in importance [28]. Getting aware of the results obtained in the current study and the status quo of the nurses can be effective on the decisions made by the managers and officials to reduce the medication errors.

\section{CONCLUSIONS}

In this study, the results indicated that the rate of medication errors is very high among the nurses. Therefore, there is a need for making serious decisions regarding the medication errors reduction. In total, medication errors even very trivial ones cause side effects in the patients, so in order for such errors to be reduced and it is suggested that relearning classes concerning the pharmacological information should be hold and education process should be modified.

\section{ACKNOWLEDGMENT}

This study was the result of a student research project approved at Zahedan University of Medical Sciences. Hereby, we express our deep gratitude to those people who participated and collaborated in this study and Research authorities of Zahedan University of Medical Sciences, who helped us in the process of data collection and financial support.

\section{REFERENCES}

1. Jahantigh M, Zare S, Shahrakipour M. The survey of the relationship between ethical climate and ethical behavior in nurses. Der Pharm Lett 2016;8(3):189-93.

2. Miandoab NY, Shahrakipour M, Zare S. The study of relationship between the ethical climate and job interestedness. Der Pharm Lett 2016;8(3):86-90.

3. Mohammad Nejad S, Hojjati H, Ehsani R. The amount and type of medication errors in nursing students in four teaching hospitals of Tehran. J Med Ethics Hist Winter 2008:88

4. Mrayyan MT, Shishani K, Al-Faouri I. Rate, causes and reporting of medication errors in Jordan: Nurses' perspectives. J Nurs Manag 2007;15(6):659-70.

5. Stetler CB, Morsi D, Burns M. Physical and emotional patient safety. A different look at nursing-sensitive outcomes. Outcomes Manag Nurs Pract 2000;4(4):159-65.

6. Hughes RG, Ortiz E. Medication errors: Why they happen, and how they can be prevented. J Infus Nurs 2005;28 2 Suppl:14-24.

7. Najafi H. Medication Prescription Error is One of the Most Common Errors in Medical Professional. Proceedings of the $1^{\text {st }}$ International Congress of Forensic Medicine. 2009. p. 25-7.

8. Jolaee S, Hajibabaee F, Peyravi H, Haghani H. Nursing medication errors and its relationship with work condition in Iran University of Medical Sciences. Iran J Med Ethics Hist Med 2009;3(1):65-76.

9. Brown MM. Managing medication errors by design. Crit Care Nurs Q 2001;24(3):77-97.

10. Souzani A, Bagheri H, Pourheydari M. Survey nurse's view about factors affects medication errors in different care units of Imam Hossein hospital in Shahroud. Knowl Health 2007;2(3):8-13.

11. Handler SM, Perera S, Olshansky EF, Studenski SA, Nace DA, Fridsma DB, et al. Identifying modifiable barriers to medication error reporting in the nursing home setting. J Am Med Dir Assoc 2007;8(9):568-74

12. Cousins DH, Sabatier B, Begue D, Schmitt C, Hoppe-Tichy T. Medication errors in intravenous drug preparation and administration: A multicentre audit in the UK, Germany and France. Qual Saf Health Care 2005;14(3):190-5.

13. Carlton G, Blegen MA. Medication-related errors: A literature review of incidence and antecedents. Annu Rev Nurs Res 2006;24:19-38.

14. McDowell SE, Ferner HS, Ferner RE. The pathophysiology of medication errors: How and where they arise. Br J Clin Pharmacol 2009;67(6):605-13.

15. Amir M, Tahereh MG, Ali ZB, Elham HS. Survey of the medication errors and refusal to report medication errors from the viewpoints of nurses in hospitals affiliated to Isfahan university of medical sciences, Iran. Health Syst Res 2013;9(1):76-85.

16. Lisby M, Nielsen LP, Mainz J. Errors in the medication process: Frequency, type, and potential clinical consequences. Int J Qual Health Care 2005;17(1):15-22.

17. Stratton KM, Blegen MA, Pepper G, Vaughn T. Reporting of medication errors by pediatric nurses. J Pediatr Nurs 2004;19(6):385-92

18. Cassiani SH. Patient safety and the paradox in medication use. Rev Bras Enferm 2005;58(1):95-9.

19. Benner P, Sheets V, Uris P, Malloch K, Schwed K, Jamison D. Individual, practice, and system causes of errors in nursing: A taxonomy. J Nurs Adm 2002;32(10):509-23.

20. Dehghan-Nayeri N, Bayat F, Salehi T, Faghihzadeh S. The effectiveness of risk management program on pediatric nurses' medication error. Iran J Nurs Midwifery Res 2013;18(5):371-7.

21. Kendall-Gallagher D, Blegen MA. Competence and certification of registered nurses and safety of patients in intensive care units. Am J Crit Care 2009;18(2):106-13.

22. Seidi M, Zardosht R. Survey of nurses' viewpoints on causes of medicinal errors and barriers to reporting in pediatric units in hospitals of Mashhad university of medical sciences. J Fasa Univ Med Sci 2012;2(3):142-7.

23. Dean BS, Allan EL, Barber ND, Barker KN. Comparison of medication errors in an American and a British hospital. Am J Health Syst Pharm 1995;52(22):2543-9.

24. Prot S, Fontan JE, Alberti C, Bourdon O, Farnoux C, Macher MA, et al. Drug administration errors and their determinants in pediatric in- patients. Int J Qual Health Care 2005;17(5):381-9.

25. Haw CM, Dickens G, Stubbs J. A review of medication administration errors reported in a large psychiatric hospital in the United Kingdom. Psychiatr Serv 2005;56(12):1610-3.

26. Wolf ZR, Hicks R, Serembus JF. Characteristics of medication errors made by students during the administration phase: A descriptive study. J Prof Nurs 2006;22(1):39-51.

27. Cavell GF, Oborne CA. Anonymously reported medication errors: The tip of the iceberg. Int J Pharm Pract 2001;9 Suppl:52.

28. Guchelaar HJ, Colen HB, Kalmeijer MD, Hudson PT, Teepe-Twiss IM Medication errors: Hospital pharmacist perspective. Drugs 2005;65(13):1735-46. 